\title{
On Object Specificity ${ }^{*}$
}

\author{
Wei-Tien Dylan Tsai \\ National Tsing Hua University \\ wttsai@mx.nthu.edu.tw
}

\section{$1 \quad$ Introduction}

In general, object shift occurs in Chinese only when contrastive focusing is involved. In indicative sentences, numeral NPs survive object shift only when they are specific or definite. This is shown by the contrast between (1a) and $(1 \mathrm{~b}, \mathrm{c}):^{1}$

(1) a. *wo liang-ben shu nian-guo, san-ben shu mei nian-guo.

I two-Cl book read-Exp three-Cl book have-not read-Exp

'I read two books, not three.'

b. wo you liang-ben shu nian-guo, you san-ben shu mei nian-guo. I have two-Cl book read-Exp have three-Cl book have-not read-Exp 'I read two of the books, but not the other three.' (specific)

c. wo zhe liang-ben shu nian-guo, na san-ben shu mei nian-guo. I this two-Cl book read-Exp that three-Cl book have-not read-Exp 'I read these two books, but not those three.' (definite)

Here the numeral object NP liang-ben shu 'two books' is in a preverbal position, and it must be bound either by the existential modal you 'have', as in (1b), or by a demonstrative like zhe 'this', as in (1c). Otherwise the sentence is simply out, as in (1a). ${ }^{2}$

However, this requirement is not observed when a modal is present. This point can be seen by comparing $(2 a, b)$ with ( $1 a)$ :

(2) a. wo liang-ben shu nian-de-wan, san-ben shu jiu bu xing le.

I two-Cl book read-can-finish three-Cl book then not possible Inc

'I can finish two books, not three.' (nonspecific)

\footnotetext{
* I would like to express my gratitude to Lisa Cheng, Gasde Horst-Dieter, Paul Law, Thomas Lee, Sze-wing Tang for sharing their thoughts with me. I am also in great debt to Niina Zhang and Chris Wilder, without whose friendship and encouragement I wouldn't have enough drive to finish this paper.

1 The abbreviations used in this paper are glossed as follows: $\mathrm{Cl}$ : classifier; Exp: experiential aspect; Inc: inchoative aspect; Prf: perfective aspect; Prg: progressive aspect; Top: topic marker.

${ }^{2}$ The jdea that object shift induces specificity is certainly not new. See Mahajan (1990), Enç (1991), Diesing (1992) for discussions on the syntax and semantics of specific NPs in various languages.
} 
b. wo liang-ben shu keyi nian-wan, san-ben shu jiu bu xing le. I two-Cl book can read-finish three-Cl book then not possible Inc 'I can finish two books, not three.' (nonspecific)

Here the numeral object NP liang-ben shu 'two books' is again in a preverbal position. The difference lies in the fact that the presence of an infixal modal -de-in (2a) and the presence of a modal verb keyi 'can' in (2b) license the otherwise ungrammatical sentence.

This indicative-modal asymmetry is reminiscent of a similar contrast of Chinese numeral NPs in subject positions, which has been under close examination in the literature (see, for instance, Lee 1986, Li 1996, Tsai 2001, among many others). As shown by the contrast between (3a) and $(3 \mathrm{~b}, \mathrm{c})$, nonspecific indefinites are not allowed in the subject position of an indicative sentence.

(3) a.* liu-ge ren tai-qi-le na-kuai shitou. six-Cl person lift-up-Prf that-Cl rock 'Six persons have lifted that rock.' (nonspecific)

b. you liu-ge ren tai-qi-le na-kuai shitou. have six- $\mathrm{Cl}$ person lift-up-Prf that-Cl rock 'There are six persons who have lifted that rock.' (specific)

c. na liu-ge ren tai-qi-le na-kuai shitou. that six-Cl person lift-up-Prf that-Cl rock 'Those six persons have lifted that rock.' (definite)

While subject NPs are ruled out when they are nonspecific, as in (3a), similar construals are licensed either with the existential modal you, as in (3b), or with the demonstrative $z h e$, as in (3c). By contrast, nonspecific NPs are quite comfortable serving as the subject of a modal construction, as evidenced by (4a) and (4b):

(4) a. liu-ge ren tai-de-qi na-kuai shitou. six- $\mathrm{Cl}$ person lift-can-up that-Cl rock

'Six persons can lift that rock.' (nonspecific)

b. liu-ge ren keyi tai-qi na-kuai shitou. six-Clperson can lift-up that-Cl rock 'Six persons can lift that rock.' (nonspecific)

Nonetheless, when it comes to bare NPs in Chinese, the situation gets a bit murky: The interpretations of fronted object NPs seems sensitive to the choice of tense. As shown by $(5 a, b)$, bare NPs can be either definite or nonspecific under realis tense in postverbal object positions: 
(5) women zuotian chi-le zhurou, qiantian chi-le niurou. we yesterday eat-Prf pork day-before-yesterday eat-Prf beef

a. '(As for the meat in the refrigerator,) we have eaten the pork yesterday, and the beef the day before yesterday.'

(definite)

b. '(As for dinner, yesterday we have eaten pork, not beef.'

(nonspecific)

There are therefore two ways to interpret (5): If the conversation has to do with the meat in the refrigerator, for example, then the reading is definite, as in (5a). If it is about the dinner, the reading is nonspecific, as in (5b). Once object shift applies, only the definite reading is available, as indicated by the contrast between $(6 \mathrm{a}, \mathrm{b})$ :

(6) women zuotian zhurou chi-le, niurou mei chi.

we yesterday pork eat-Prf beef have-not eat

a. '(As for the meat in the refrigerator,) yesterday we have eaten the pork, not the beef.'

(definite)

b.\# '(As for dinner, yesterday we have eaten pork, not beef.' (nonspecific)

By contrast, sentences with irrealis tense behave quite differently: While bare NPs can be either definite or nonspecific in postverbal object positions, as in $(7 \mathrm{a}, \mathrm{b})$, both the definite and nonspecific readings survive object shift, as indicated by the ambiguity of $(8 a, b)$ :

(7) women mingtian chi zhurou, houtian chi niurou.

we tomorrow eat pork day-after-tomorrow eat beef

a. '(As for the meat in the refrigerator,) we will eat the pork for tomorrow, and the beef for the day after tomorrow.' (definite)

b. '(As for dinner, we will eat pork for tomorrow, and beef for the day after tomorrow.' (nonspecific)

(8) women mingtian zhurou chi, niurou bu chi. we tomorrow pork eat beef not eat

a. '(As for the meat in the refrigerator,) tomorrow we will eat the pork, but not the beef.'

b. '(As for dinner,) tomorrow we will eat pork, but not beef.' (nonspecific)

Moreover, when we shift the bare object NP further across temporal adverbials such as zuotian 'yesterday' and mingtian 'tomorrow', the only possible reading in both cases is definite, as evidenced by (9) and (10) respectively:

(9) women zhurou zuotian chi-le, niurou qiantian chi-le. we pork yesterday eat-Prf beef day-before-yesterday eat-Prf

a. '(As for the meat in the refrigerator,) we have eaten the pork yesterday, and the beef for the day before yesterday.' (definite)

b. \#'(As for the dinner,) we have eaten pork yesterday, and beef the day before yesterday.' (nonspecific) 
(10) women zhurou mingtian chi, niurou houtian chi. we pork tomorrow eat beef day-after-tomorrow eat

a. '(As for the meat in the refrigerator,) we will eat the pork for tomorrow, and the beef for the day after tomorrow.' (definite)

b.\# '(As for the dinner, ) we will eat pork for tomorrow, and beef for the day after tomorrow.' (nonspecific)

In other words, the distinction between realis tense and irrealis tense is neutralized when the object NP in question is raised over temporal adverbials.

The distributive-interpretive pattern of Chinese object specificity can then be summarized in the following table:

Table 1.

\begin{tabular}{|l|l|l|l|l|}
\hline \multicolumn{2}{|c|}{} & pre-adverbial & in-between & post-verbal \\
\hline \multirow{3}{*}{ realis } & definite & yes & yes & yes \\
\cline { 2 - 5 } & nonspecific & no & no & yes \\
\hline \multirow{2}{*}{ irrealis } & definite & yes & yes & yes \\
\cline { 2 - 5 } & nonspecific & no & yes & yes \\
\hline
\end{tabular}

As shown above, the definite reading is always there as an option, whereas the non-specific reading is on and off depending on the choice of tense, and on the syntactic position where a given object NP occurs.

In this paper, we would like to explore the possibility of deriving the subject and object specificity in a principled and unified way, mainly through the so-called Extended Mapping Hypothesis developed in Tsai $(1999,2001)$. Section 1 and 2 give an overview of how the issues with subject specificity can be approached from a vantage point of the syntaxsemantics interface. In section 3 , we proceed to show that subject specificity and object specificity are basically the same phenomena, except for a few twists on their licensing conditions. Section 4, on the other hand, provides a brief review on the interpretations of bare NPs in Chinese. Finally, in section 5, it is argued that the realis-irrealis distinction based on the interpretation of object indefinites follows from a more general dichotomy between indicative and modal constructions.

\section{A Dynamic View of Syntax-Semantics Mapping}

Let's first consider the following two questions: Is there a unified solution to the subject and object specificity? Can we provide a principled account of the asymmetry between the indicative and modal constructions? Diesing (1992) has provided an explicit answer to the former, based on the well-known tree-splitting mechanism (11): 
(11) Mapping Hypothesis:

a. Material from VP is mapped into the nuclear scope.

b. Material from IP (excluding VP) is mapped into a restrictive clause.

The mapping mechanism maps a GB-theoretical representation to a tripartite quantificational structure, including a quantifier, its restrictive clause, and the nuclear scope (Kamp 1981 and Heim 1982). In addition, it is claimed that existential closure applies to VP, rather than to IP or Text as originally proposed by Heim. It is instructive to note that the above mechanism doesn't seem to have a global character, since existential closure is in general clause-bound. Consequently, we need to define the domain of existential closure locally, and implement mapping step by step, as stated in (12), a more "dynamic" version of the Mapping Hypothesis (Tsai 1999, 2001):

(12) Extended Mapping Hypothesis (EMH):

a. Mapping applies cyclically, and vacuous quantification is checked derivationally.

b. Material from a syntactic predicate is mapped into the nuclear scope of a mapping cycle.

c. Material from XP immediately dominating the subject chain of a syntactic predicate (excluding that predicate) is mapped outside the nuclear scope of a mapping cycle. A subject chain is an A-chain with its tail in a subject position.

d. Existential closure applies to the nuclear scope of a mapping cycle.

Under this approach, the focus of inquiry is shifted to how to define a local domain of syntaxsemantics mapping, i.e., a "mapping cycle".

On the other hand, the Mapping Hypothesis doesn't have much to say about the indicative-modal asymmetry illustrated above. To provide a feasible answer, we would like to establish a typological correlation between the absence of nonspecific subjects and the absence of V-to-I movement. Namely, in a V-to-I language like English, the domain of a primary predicate, as well as the corresponding nuclear scope, is extended from $\mathrm{V}^{\prime}$ to $\mathrm{I}^{\prime}$ in $\mathrm{LF}$, as dictated by $(12 b, c)$. Given the VP-internal subject hypothesis, a subject chain typically has its head above the nuclear scope, while submerging its tail under the nuclear scope, as shown in the diagram (13):

(13) English type

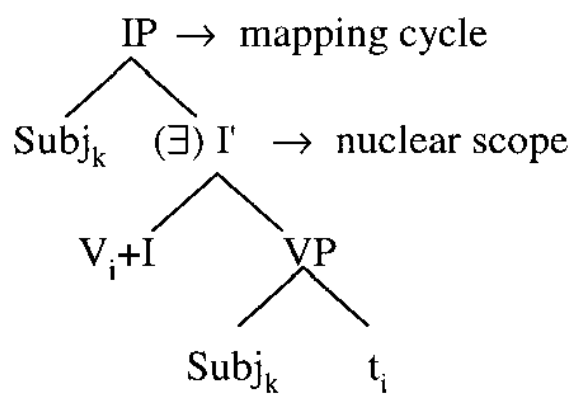


This move leads us to examine the issue further from the vantage point of Chomsky's (1995) Copy Theory: If the lower copy in Spec-VP is deleted, the upper copy in Spec-IP must get strongly quantified, either by its own determiner or by a sentential operator like an adverb of quantification. This is because existential closure is not available at this altitude. If the upper copy is deleted, then the lower copy is licensed by existential closure introduced according to (12d).

By contrast, Chinese-type languages lack agreement morphology, and do not license Vto-I raising. As a result, a subject chain is typically outside nuclear scope, and cannot be saved by existential closure on V', the de facto syntactic predicate, as illustrated by (14):

(14) Chinese type

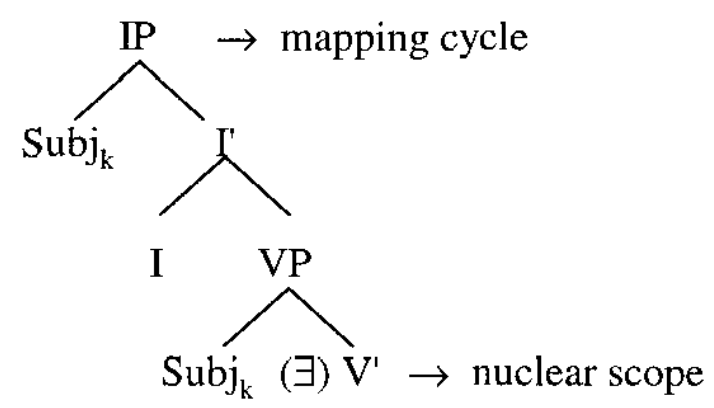

This move provides a straightforward account of the contrast between (15a) and (15b,c) ( (3ac) repeated here):

a. * liu-ge ren tai-qi-le na-kuai shitou. six-Cl person lift-up-Prf that-Cl rock

'Six persons have lifted that rock.' (nonspecific)

b. you liu-ge ren tai-qi-le na-kuai shitou.

have six- $\mathrm{Cl}$ person lift-up-Prf that- $\mathrm{Cl}$ rock

'There are six persons who have lifted that rock.' (specific)

c. na liu-ge ren tai-qi-le na-kuai shitou.

that six- $\mathrm{Cl}$ person lift-up-Prf that-Cl rock

'Those six persons have lifted that rock.' (definite)

In (15a), the subject chain is outside the nuclear scope, and the numeral liu 'six' cannot serve as a strong determiner in Milsark's (1974) sense. (15a) is therefore ruled out due to vacuous quantification. By contrast, the subject indefinites of $(15 \mathrm{~b}, \mathrm{c})$ are licensed by the existential modal you 'have' and the demonstrative na 'that' respectively.

\section{$3 \quad$ Mapping Geometry of Subject Indefinites}

Interestingly enough, we often observe the English type behavior in Chinese modal constructions, where it is not unusual to find overt verb raising from $\mathrm{V}$ to Mod, as shown in 
(16a) ((4a) repeated here):

(16) a. liu-ge ren tai-de-qi na-kuai shitou. six-Cl person lift-can-up that- $\mathrm{Cl}$ rock 'Six persons can lift that rock.' (nonspecific)

b. liu-ge ren keyi tai-qi na-kuai shitou. six-Clperson can lift-up that- $\mathrm{Cl}$ rock 'Six persons can lift that rock.' (nonspecific)

In (16a), the compound tai-qi 'lift-up' raises to the infixal modal -de- 'can', creating a mapping geometry very similar to the one in the English type configuration (13), as sketched in the following diagram:

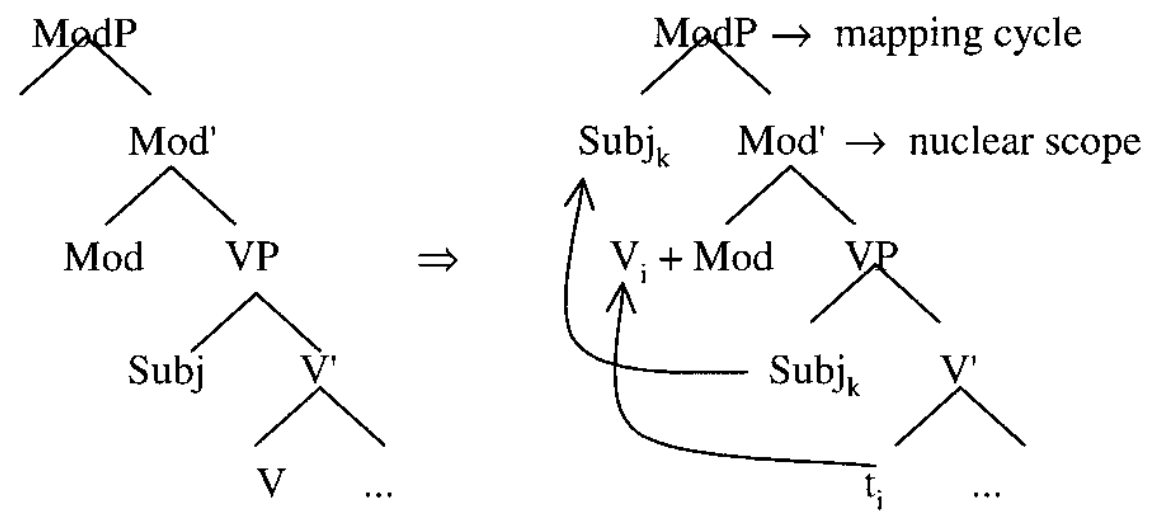

Therefore, we would like to entertain the hypothesis that the mapping geometry of Chinese modal sentences is isomorphic to that of English indicatives, to the extent that verb raising is limited to a light or modal verb, rather than to a higher functional category such as $\mathrm{T}$ or Agr. ${ }^{3}$ As a result, the subject indefinite of (16a) can be licensed by existential closure when the upper copy of the subject chain undergoes LF deletion, as illustrated below:

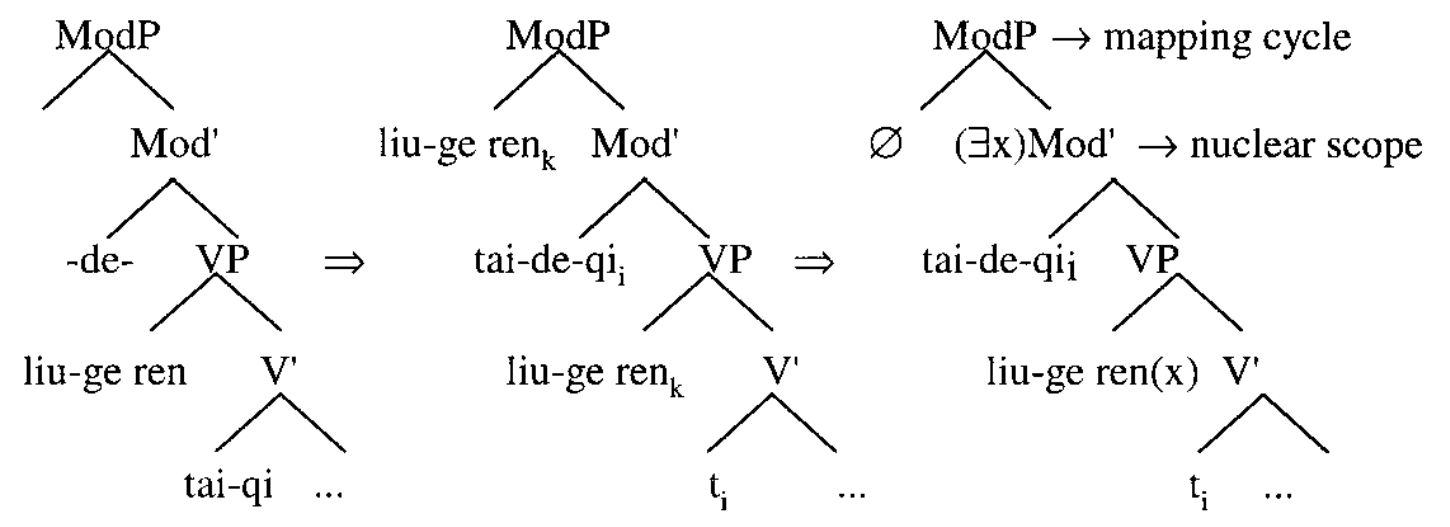

This move accounts for the nonspecific reading of (16a). The same analysis carries over to (16b) except that V-to-Mod raising applies in LF rather than in overt syntax, as shown by the

\footnotetext{
${ }^{3}$ In contrast to V-to-I raising, raising to a light verb or a modal verb is quite common in Chinese. For detailed discussion, see Huang (1994, 1997) and Lin (2000).
} 
derivation of (19):

(19)

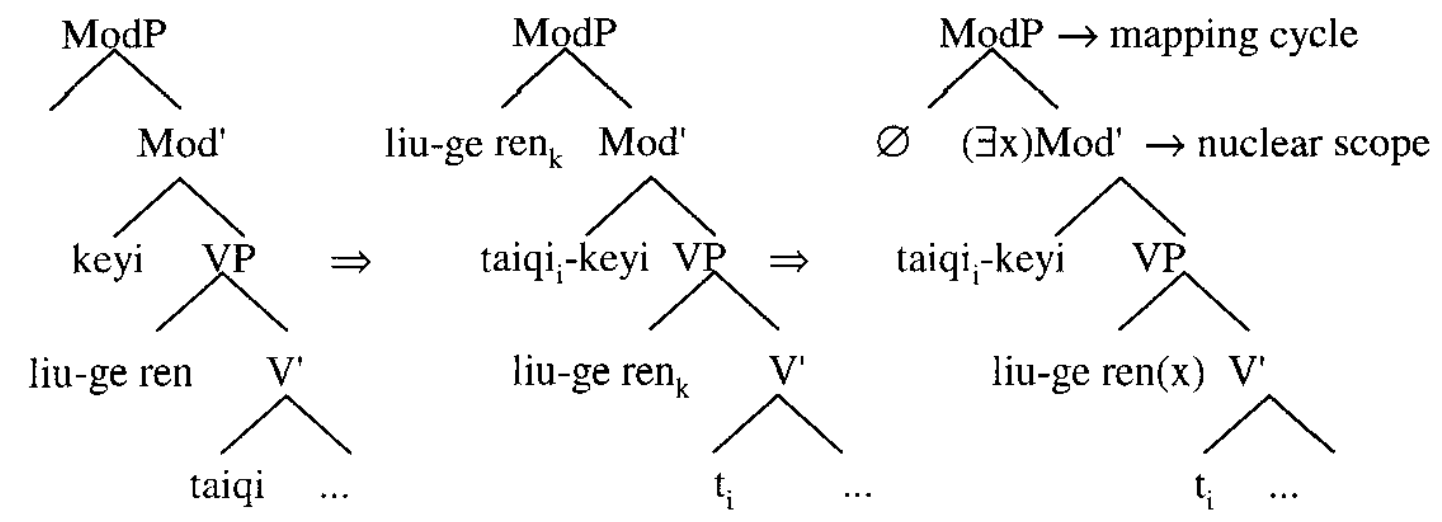

In other words, the indefinite subject gets its nonspecific reading through existential closure on Mod', given the EMH (12a-d).

\section{$4 \quad$ Mapping Geometry of Object Indefinites}

For all we have said about the subject specificity, one may well wonder whether the same story can be told about the indicative-modal asymmetry between ( $1 \mathrm{a})$ and (2a,b) (repeated here as (20a) and $(20 \mathrm{~b}, \mathrm{c})$ respectively):

(20) a. *wo liang-ben shu nian-guo, san-ben shu mei nian-guo.

I two-Cl book read-Exp three-Cl book have-not read-Exp

'I read two books, not three.'

b. wo liang-ben shu nian-de-wan, san-ben shu jiu bu xing le. I two-Cl book read-can-finish three-Cl book then not possible Inc 'I can finish two books, not three.' (nonspecific)

c. wo liang-ben shu keyi nian-wan, san-ben shu jiu bu xing le. I two-Cl book can read-finish three- $\mathrm{Cl}$ book then not possible Inc 'I can finish two books, not three.' (nonspecific)

First consider the following mapping geometry of $(20 \mathrm{~b}, \mathrm{c})$ after object shift occurs: 
(21)

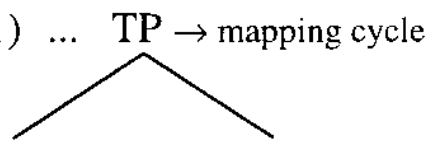

Subj $j_{\mathrm{i}}$

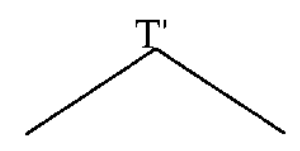

$\mathrm{T}$

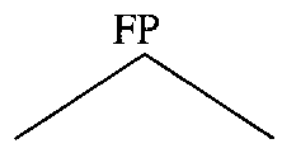

$\mathrm{Obj}_{\mathrm{k}}$

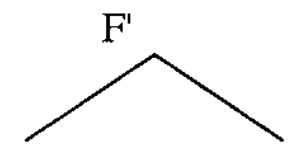

$\mathrm{F}$

(ヨ) ModP $\rightarrow$ nuclear scope

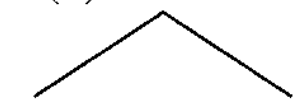

$\mathrm{V}_{\mathrm{j}}-\mathrm{Mod}$

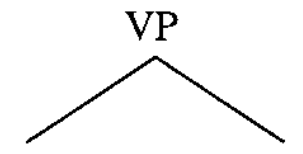

Subji $_{\mathrm{i}}$

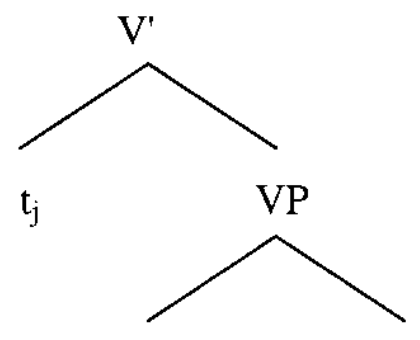

$\mathrm{Obj}_{\mathrm{k}}$

Here both the subject chain and the object chain have their tails submerged under the nuclear scope, and thus subject to existential closure. Since the verb has been raised to Mod (overtly in (20b) and covertly in (20c)), the predicate domain has been extended to ModP, which in turn forms the nuclear scope. Now if the lower object copy undergoes LF deletion, the upper copy in Spec-FP must get extra licensing since it is outside the nuclear scope. However, this is impossible because Chinese numerals cannot serve as a strong determiner. Alternatively, if it is the upper object copy that is deleted in LF, the lower copy is then subject to existential closure. Hence the nonspecific reading of $(20 \mathrm{~b}, \mathrm{c})$.

It follows from our treatment that both the subject and object indefinites can be nonspecific in the modal construction. This is indeed the case, as evidenced by (22a,b):

(22) a. san-ge ren liu-wan fan chi-de-wan, jiu-wan fan jiu bu xing le. three-Cl person-Cl six-Cl rice eat-can-finish nine- $\mathrm{Cl}$ book then not possible Inc 'Three persons can finish six bowls of rice, not nine.' (nonspecific)

b. san-ge ren liu-wan fan keyi chi-wan, jiu-wan fan jiu bu xing le. three- $\mathrm{Cl}$ person- $\mathrm{Cl}$ six-Cl rice can eat-finish nine- $\mathrm{Cl}$ book then not possible Inc 'Three persons can finish six bowls of rice, not nine.' (nonspecific) 
Note that there are altogether four possibilities of interpreting $(22 a, b)$ given the Copy Theory, as illustrated below:

(23) a. $\operatorname{Subj}_{\mathrm{i}} \ldots \mathrm{Obj}_{\mathrm{k}} \ldots[$ [nuclear scope $\ldots \varnothing \ldots \varnothing \ldots]$

b. $\operatorname{Subj}_{\mathrm{i}} \ldots \varnothing \ldots\left[\right.$ nuclear scope $\left.\ldots \varnothing \ldots \mathrm{Obj}_{\mathrm{k}} \ldots\right]$

c. $\varnothing \ldots \mathrm{Obj}_{\mathrm{k}} \ldots\left[\right.$ nuclear scope $\left.\ldots \operatorname{Subj}_{\mathrm{i}} \ldots \varnothing \ldots\right]$

d. $\varnothing \ldots \varnothing \ldots\left[\right.$ nuclear scope $\left.\ldots . . \operatorname{Subj}_{\mathrm{i}} \ldots \mathrm{Obj}_{\mathrm{k}} \ldots\right]$

In (23a), both the lower subject and object copies are deleted, leaving the upper copies outside the nuclear scope, and hence outside of the domain of existential closure. Since there is no sentential operator around either, we should dismiss this possibility in view of vacuous quantification. (23b) and (23c) are ruled out for exactly the same reason except that there is only one offending indefinite in each case, i.e., the upper subject copy in the former and the upper object copy in the latter. Consequently, the only possible interpretation turns out to be (23d), where both the upper copies are deleted, and the lower copies are licensed under existential closure on the nuclear scope. The dual nonspecific readings of $(22 a, b)$ thus follows quite naturally from our account.

By contrast, the case with (20a) is more problematic: As shown by (24), when an object stays in situ in an indicative sentence, the reading is unambiguously specific:

(24) wo nian-guo liang-ben shu.

I read-Exp two-Cl book

'I read two books.' (specific)

Here the crucial factor lies in the aspectual licensing from - guo, an experiential aspect in $\mathrm{Li} \&$ Thompson's (1981) terms. The dependency can then be formalized as an instance of unselective binding between the aspectual operator and the variable introduced by the numeral NP, as visualized in the following diagram:

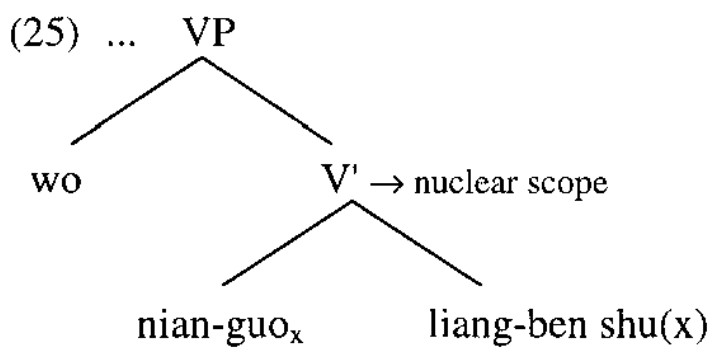

This observation raises the issue as to why (20a) cannot be saved in the way described in (25), i.e., by assigning a specific reading to the object indefinite: When the lower object copy is deleted, the upper copy is outside the nuclear scope (hence outside the domain of existential closure), resulting in vacuous quantification, as in (26): 
(26)

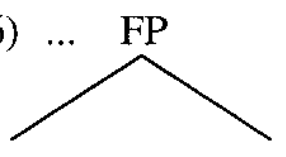

$\operatorname{Obj}(\mathrm{x})$

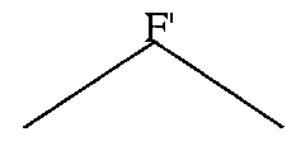

$\mathrm{F}$

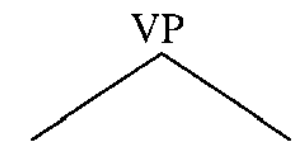

Subj

(ヨ) $\mathrm{V}^{\prime} \rightarrow$ nuclear scope

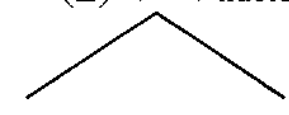

V-Exp

$\varnothing$

When the upper object copy is deleted, the lower copy is subject to the licensing from the experiential aspect, as in (27):

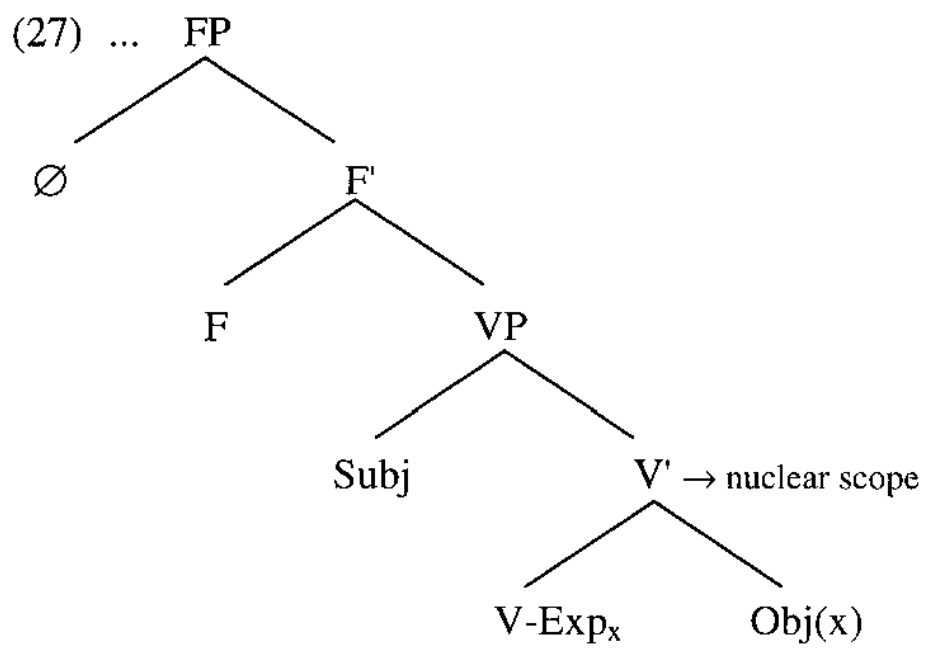

This seems to be a natural consequence from what we have seen in (25), which, nonetheless, is not borne out.

One way to approach the problem is to say that aspectual licensing, in contrast with existential closure, only licenses a trivial chain (that is, a chain with only one member). Alternatively, it may well be the case that aspectual licensing, in contrast with existential closure, applies to a chain rather than a member of the chain: In other words, the whole chain has to be under the scope of the aspectual operator to get a specific reading. We will leave the choice open here, while concentrating on finding a feasible solution to the indicative-modal asymmetry in general.

\section{Interpreting Chinese Bare NPs}

Before we go any further, it is worthwhile to take a closer look at the semantic properties of Chinese bare NPs. Basically, if we discount generic and habitual construals, a Chinese bare NP can be either definite or non-specific, as shown by the contrast between $(28 a, b)$ : 
(28) wo zaoshang zongsuan zhao-dao ren le.

I morning finally search-reach person Inc

a. '(I could not find John to help me yesterday.) I finally found him this morning.' (definite)

b. '(I could not find anyone to help me yesterday.) I finally found somebody this morning.' (nongeneric and nonspecific)

In (28a) the bare NP ren 'person' refers to the salient individual in the discourse, and can be paraphrased as a pronoun. In (28b), there is no reference to a particular individual, and the reading is quite like somebody in English. ${ }^{4}$ Although the definite construal of (28a) is anaphoric in nature, bare NPs can be deictic sometimes, as evidenced by $(29 \mathrm{a}, \mathrm{b})$ :

(29) ren lai le!

person come Inc

a. 'That person/He/She is coming!'

b. 'Those people/They are coming!'

By contrast, as Huang (1987) points out, Chinese bare NPs can never be specific. This point can be illustrated by comparing (30) with (31):

(30) * wo zongsuan zhao-dao-le $\quad \operatorname{ren}_{\mathrm{k}} \quad\left[O \mathrm{p}_{\mathrm{k}}\left[\mathrm{t}_{\mathrm{k}}\right.\right.$ hen nenggang]].

I finally search-reach-Prf person very capable

${ }^{? ?}$ I have finally found somebody, who is very capable.

(31) wo zongsuan zhao-dao-le yi-ge $\operatorname{ren}_{k}\left[\mathrm{Op}_{\mathrm{k}}\left[\mathrm{t}_{\mathrm{k}}\right.\right.$ hen nenggang]].

I finally search-reach-Prf one-CL person very capable

'I have finally found a certain person, who is very capable.'

In (30), the bare object NP ren 'person' cannot take a secondary predicate. By contrast, the numeral object NP of (31) is capable of serving as the subject of secondary predication. According to our analysis, the subject of the local mapping cycle is outside the nuclear scope which corresponds to the open sentence headed by hen nenggang 'very capable'. If it is indeed the case that a bare NP cannot be specific, then we can rule out (30) without further stipulation.

A numeral NP, on the other hand, differs from its bare counterpart in being subject to aspectual licensing: For instance, the object indefinite of (31) is in fact unselectively bound by the perfective aspect $-l e$, which asserts the existence of the people-finding event. To see this, (31) should be further contrasted with (32), where the aspect has been changed into progressive:

(32) * wo zai-zhao yi-ge $\operatorname{ren}_{\mathrm{k}}\left[O \mathrm{p}_{\mathrm{k}}\left[\mathrm{t}_{\mathrm{k}}\right.\right.$ hen nenggang].

I Prg-find one-CL person very capable

?? I am looking for somebody, who is very capable.'

\footnotetext{
${ }^{4}$ See Cheng \& Sybesma (1999) for a comprehensive discussion on the distinction between bare and numeral NPs across Chinese dialects.
} 
Here the progressive aspect does not trigger existential quantification, and secondary predication fails because the subject of the local mapping cycle (defined by secondary predication) cannot get extra licensing.

\section{Realis Tense vs. Irrealis Tense: Indicative-modal Asymmetry Revisited}

Keeping the above discussion in mind, it's time to explore the distribution and interpretation of bare NPs in presence of object shift. First consider (8) (repeated here as (33)), where the object is fronted in-between the temporal adverbial mingtian 'tomorrow' and the main verb chi 'eat':

(33) women mingtian zhurou chi, niurou bu chi.

we tomorrow pork eat beef not eat
a. '(As for the meat in the refrigerator,) tomorrow we will eat the pork, but not the beef.'
b. '(As for dinner,) tomorrow we will eat pork, but not beef.' (nonspecific)

It is worthwhile to note that (33) can be paraphrased as (34) respectively with a future modal hui 'will' preceding the main verb:

(34) women mingtian zhurou hui chi, niurou bu hui chi.
we tomorrow pork will eat beef

a. (As for the meat in the refrigerator,) tomorrow we will eat the pork, but not the beef. (definite)

b. (As for dinner, tomorrow we will eat pork, but not beef. (nonspecific)

Given what we have seen in $(20 b, c)$, where an fronted object indefinite is licensed through possibility modality, it is a simple deduction that it may also get licensing from a epistemic modal such as hui. This intuition translates into following two parts under our approach: Firstly, (33) has an implicit future modal locating between the object indefinites and the main verbs. This modal, implicit or not, is the locus of the irrealis tense in Chinese. Secondly, the nonspecific readings of (33) should be credited to existential closure on ModP, as illustrated by the diagram (35): 
(35)

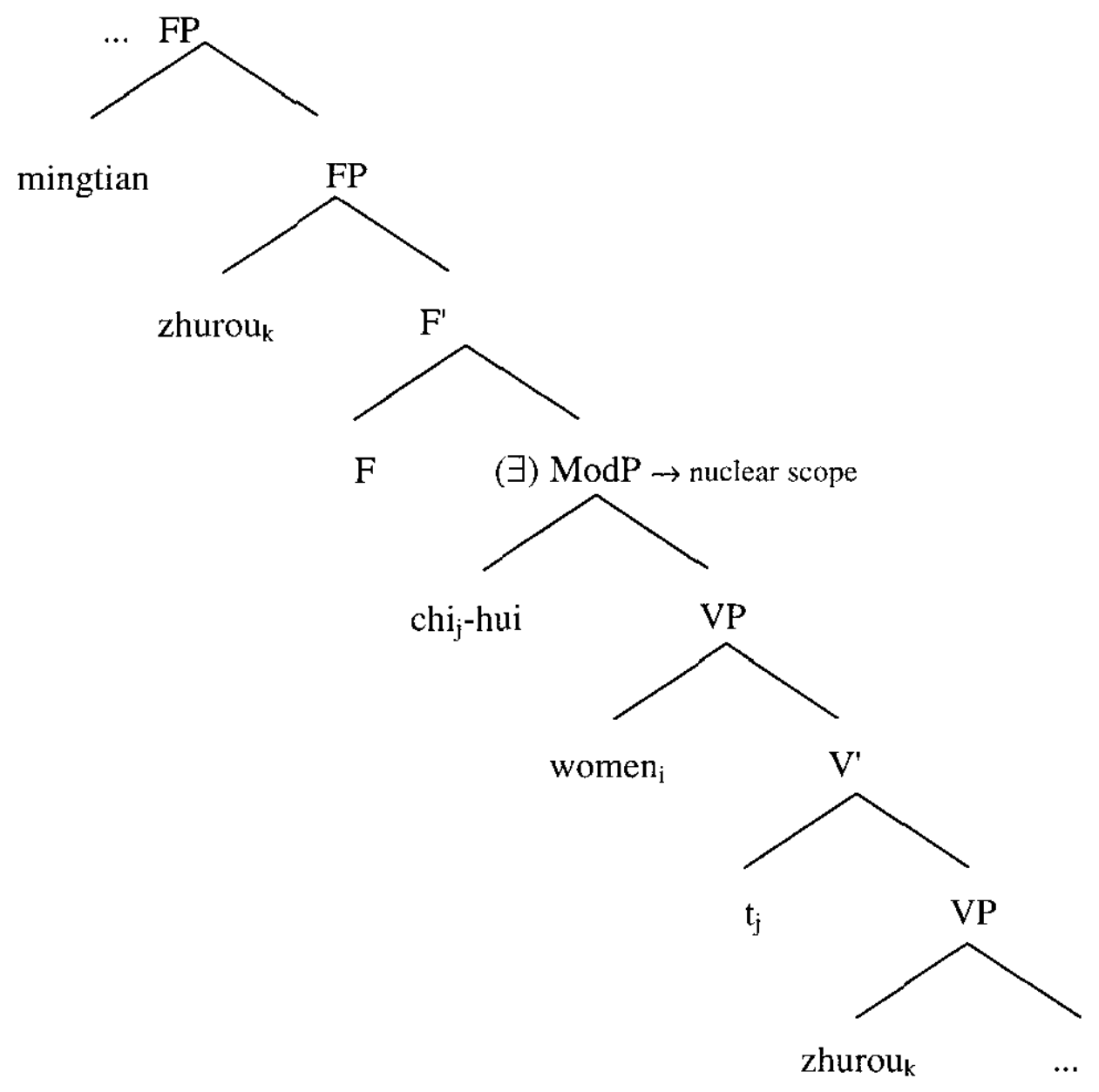

Namely, ModP serves as a syntactic predicate after $\mathrm{V}$ raises to Mod in LF, and effectively extends the nuclear scope from $V^{\prime}$ to ModP.

As we have demonstrated in the previous sections, there are essentially two ways to interpret an object chain link in terms of Copy Theory: If LF deletion applies to the lower copy, the only option left for the bare NP zhurou 'pork' is to get strongly quantified, since the upper copy is outside the domain of existential closure. This accounts for the definite readings of (33a). Alternatively, if it is the upper copy that undergoes LF deletion, then the lower copy benefits from the licensing from existential closure, resulting in the nonspecific readings of (33b). ${ }^{5}$

With the realis sentence (6) (repeated here as (36)), on the other hand, we run into the same type of problem encountered in (20a), except that this time around, bare NPs have one

\footnotetext{
5 It appears that our theory also provide a solution for the object specificity displayed by the Dutch sentences (i) and (ii):

(i) Rudy hoopt dat Onno morgen zes brieven verscheurt.

Rudy hopes that Onno tomorrow six letters tears up

'Rudy hopes that Onno will tear up six letters tomorrow.' (specific, nonspecific)

(ii) Rudy hoopt dat Onno zes brieven ${ }_{k}$ morgen $t_{k}$ verscheurt.

Rudy hopes that Onno six letters tomorrow tears up

'Rudy hopes that Onno will tear up six letters tomorrow.' (specific)

As observed by Reuland (1988), the numeral object NP of (i) can be either specific or nonspecific. If Bobaljik \& Jonas's (1996) version of Holmberg's generalization is on the right track, the numeral NP has already undergone object shift to a VP-external position. By contrast, when we raise the numeral NP further over the temporal adverbial morgen 'tomorrow', only the specific reading is available. In this case, Dutch differs from Chinese only in that the numeral can be construed as a strong determiner.
} 
more reading to keep the derivation alive, i.e., the definite interpretation of (36a):

(36) women zuotian zhurou chi-le, niurou mei chi. we yesterday pork eat-Prf beef have-not eat

a. '(As for the meat in the refrigerator,) yesterday we have eaten the pork, not the beef.'

(definite)

b.\# '(As for dinner, ) yesterday we have eaten pork, not beef.' (nonspecific)

When the bare object NP gets interpreted as definite, it doesn't matter whether it is the upper or lower copy that undergoes LF deletion, since it does not rely on existential closure to remain legitimate. By contrast, when the bare object NP gets interpreted as indefinite, the licensing conditions vary, depending on which copy is deleted at LF: When LF deletion applies to the lower copy, the variable introduced by the upper copy is left unbound, causing vacuous quantification, as shown by (37):
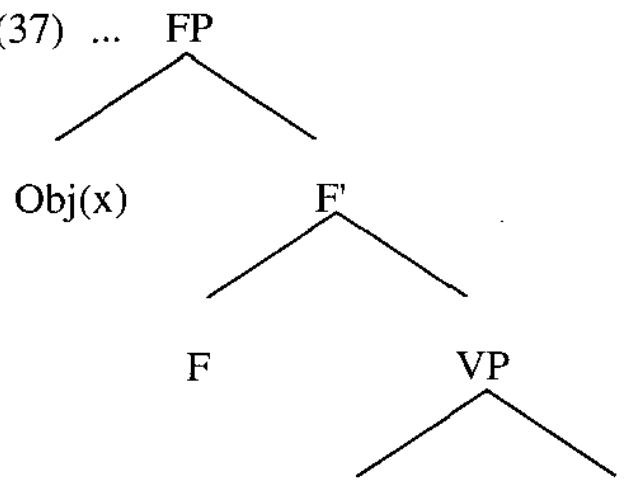

Subj
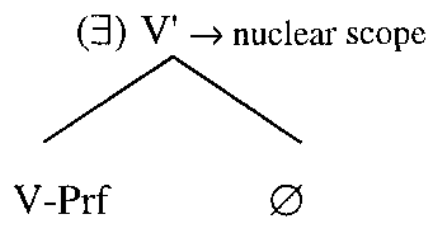

When LF deletion applies to the upper copy, the situation becomes relatively complicated, as illustrated below:

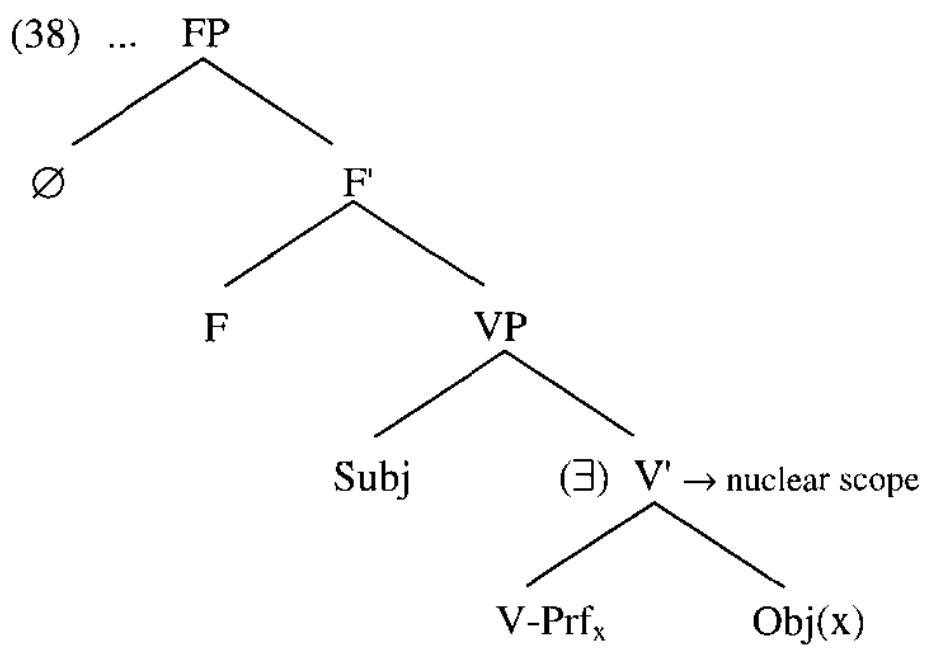


Here the lower copy is subject to the licensing from the perfective aspect $-l e$, which would results in a specific reading. This option, as we have shown in section 4 , is nonetheless incompatible with the semantics of Chinese bare NPs. The problem, therefore, is reduced to why the lower object copy cannot be bound by existential closure as a last resort, producing a nonspecific reading, as visualized in (39):

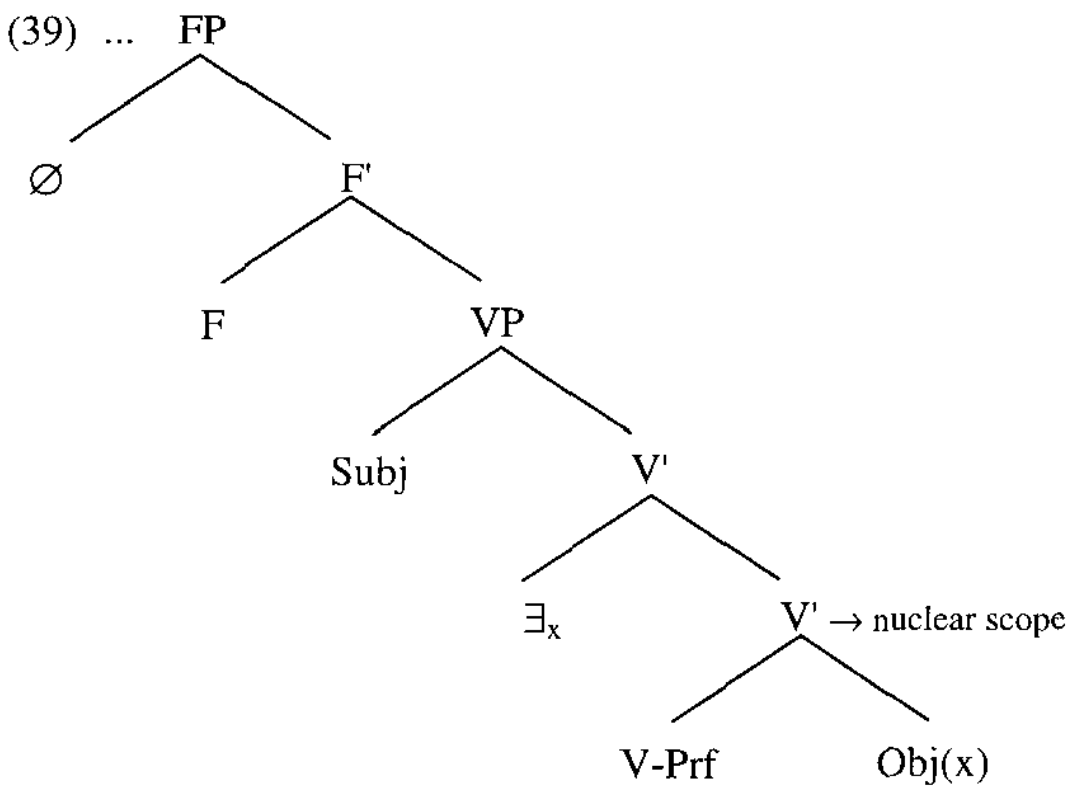

Here we would like to entertain the possibility that the licensing from existential closure is blocked by the perfective operator, which serves as a potential unselective binder. We thus have a classic case of relativized minimality violation. It turns out that the only reading available for (36) is definite, which is a desirable result.

Finally, we still have to deal with the question why the nonspecific readings are completely ruled out for pre-adverbial object indefinites. To begin with, I would like to point that (9) and (10) pattern with left dislocation structures like (40a) in allowing a resumptive pronoun:
a. $\operatorname{Akiu}_{\mathrm{k}}(\mathrm{a})$,
wo taoyan $\left(\mathrm{ta}_{\mathrm{k}}\right)$.
Akiu Top
I hate
$\operatorname{him}$
'As for Akiu, I hate him.'

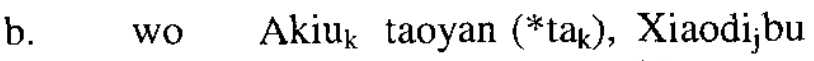
I Akiu hate him
taoyan $\left(* \mathrm{ta}_{\mathrm{j}}\right)$.
'I hate Akiu, but not Xiaodi.'
Xiaodi not hat
him

Object shift, on the other hand, disapproves the resumptive strategy, as evidenced by (40b). This observation holds regardless of the choice of tense, as indicated by the contrast of $(41 \mathrm{a}, \mathrm{b})$ and that of $(42 \mathrm{a}, \mathrm{b})$ :

(41) a.? wo Akiu zuotian jian-guo $\operatorname{ta}_{\mathrm{k}}, \ldots$

I Akiu yesterday meet-Exp him

'As for Akiu, I met him yesterday, ... 
$\begin{array}{clll}\text { b. }{ }^{*} \text { wo } & \text { zuotian } & \text { Akiu }_{\mathrm{k}} & \text { jian-guo } \\ \text { I } & \text { yesterday } & \text { Akiu meet-Exp him }\end{array}$

(42) a.? wo Akiu $_{\mathrm{k}}$ mingtian hui jian-dao $\mathrm{ta}_{\mathrm{k}}, \ldots$

I Akiu tomorrow will meet-reach him

'As for Akiu, I will meet him tomorrow, ...

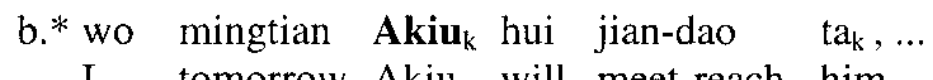

I tomorrow Akiu will meet-reach him

All these point to the conclusion that the seeming object on the pre-adverbial position is in fact a discourse topic, which is either specific or definite by nature. Since a bare NP can never be construed as specific, we correctly predict that the (9) and (10) only allow a definite interpretation.

Our position is further strengthened by the fact that numeral NPs cannot appear higher than temporal adverbials, as evidenced by (43) and (44):

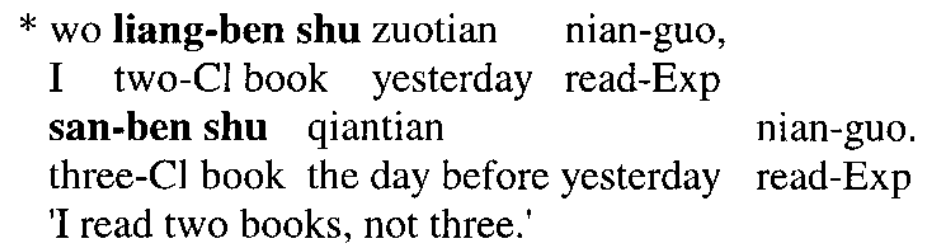

(44) * wo liang-ben shu mingtian nian-de-wan,

I two-Cl book tomorrow read-can-finish

san-ben shu houtian nian-de-wan.

three- $\mathrm{Cl}$ book the day after tomorrow read-can-finish

'I can finish two books tomorrow, and three the day after tomorrow.' (nonspecific)

The phenomenon would make sense if the pre-adverbial position hosts a discourse topic, for which a numeral NP by itself can never be qualified.

\section{$7 \quad$ Concluding Remarks}

To sum up, we have demonstrated that the object specificity follows from the same principle as the subject specificity under the EMH. Furthermore, the semantic discrepancy between the realis and irrealis object shift constructions turns out to be a subcase of the more general indicative-modal asymmetry. Although our analysis presented here is nothing but conclusive, it does suggest that the EMH is a potent candidate for explaining the indicative-modal asymmetry, as well as for building a general theory of the specificity effects in question.

\section{References}

Chomsky, Noam (1993) "A Minimalist Program for Linguistic Theory," in Kenneth Hale and Samuel Jay Keyser (eds.) The View from Building 20: Essays in Linguistics in Honor of Sylvain Bromberger, 1-52, MIT Press, Cambridge, MA.

Chomsky, Noam (1995) The Minimalist Program, MIT Press, Cambridge, MA.

Diesing, Molly (1992) Indefinites, MIT Press, Cambridge, MA.

Enç, Murvet (1991) "The Semantics of Specificity," Linguistic Inquiry 22, 1-25. 
Heim, Irene (1982) The Semantics of Definite and Indefinite Noun Phrases, PhD Dissertation, University of Massachussets, Amherst.

Huang, C.-T. James (1987) "Existential Sentences in Chinese and (In)definiteness," in Reuland, Eric \& Alice ter Meulen (eds.) The Representation of (In)definiteness, 226-253, MIT Press, Cambridge, MA.

Huang, C.-T. James (1994) "Verb Movement and Some Syntax-Semantics Mismatches in Chinese," Chinese Languages and Linguistics 2, 587-613.

Huang, C.-T. James (1997) "On Lexical Structure and Syntactic Projection," Chinese Languages and Linguistics $3,45-89$.

Kamp, J. A. W. (1981) "A Theory of Truth and Semantic Representation," in J. Groenendijk, T. Janssen, and M. Stokhof (eds.) Formal Methods in the Study of Language, 277-321, Mathematical Centre, Amsterdam.

Lee, Thomas (1986) Studies on Quantification in Chinese, PhD Dissertation, UCLA.

Li, Y.-H. Audrey (1996) "Indefinite Subject in Mandarin Chinese," ms., USC.

Lin, Tzong-hong Jonah (2000) "Unselectiveness of Subject and Object in Chinese and a Typology of Phrase Structure," in Proceedings of the Nanzan GLOW, 257-274.

Mahajan, Anoop (1990) The A/A-bar Distinction and Movement Theory, PhD Dissertation, MIT.

Milsark, Gary (1974) Existential Sentences in English, PhD Dissertation, MIT.

Reuland, Eric (1988) "Indefinite Subjects," in Proceedings of NELS 18, 375-394, GLSA University of Massachusetts, Amherst.

Tsai, Wei-Tien Dylan (1999) On Economizing the Theory of A-bar Dependencies, Garland, New York [MIT PhD Dissertation, 1994].

Tsai, Wei-Tien Dylan (2001) "On Subject Specificity and Theory of Syntax-Semantics Interface," Journal of East Asian Linguistics 10, 129-168.

Graduate Institute of Linguistics National Tsing Hua University

Hsinchu 300

Taiwan

E-mail: wttsai@mx.nthu.edu.tw 